\title{
The Do-Not-Resuscitate Order: A Comparison of Physician and Patient Preferences and Decision-Making
}

MARK H. EBELL, M.D., DAVID J. DOUKAS, M.D., Mindy A. SMITH, M.D., Ann Arbor, Michigan

PURPOSE: The purpose of this study was to compare the decision-making and preferences regarding do-not-resuscitate (DNR) orders of a group of family physicians with a group of outpatients from a family practice center. Complete results of the outpatient questionnaire were published in a previous study by the authors.

SUBJECTS AND METHODS: A random sample of 202 members of the Michigan Academy of Family Practice and all 32 members of the University of Michigan Department of Family Practice were surveyed by a mailed questionnaire. The questionnaire was divided into five parts: demographics, past experiences with DNR orders, who should be involved in DNR decision-making, values clarification, and a series of scenarios matched by a variety of biomedical and non-biomedical factors.

RESULTS: After eliminating physicians who had left no forwarding address or who had retired or died, the overall response rate was $61.8 \%$. Most physicians (97\%) had at some time written a DNR order for one of their patients; discussions most commonly took place in the hospital room. Physicians, like patients, thought that in addition to the patient, DNR decisions should involve the spouse, the physician, and the patient's children, respectively. Value clarification revealed that both groups most highly value "being able to think clearly" and "being treated with dignity." The presence of a number of quality-of-life issues (age, drug or alcohol use, wheelchair use, dementia, and severe pain) in a series of scenarios negatively affected the decision of both family physicians and patients to resuscitate.

CONCLUSION: There are significant similarities and differences in the way physicians and patients make DNR decisions. It is important that physicians and their patients communicate in a timely manner about prognosis, values, and quality-of-life issues in order to make effective DNR decisions.

From the Department of Family Practice, University of Michigan, Ann Arbor, Michigan.

Requests for reprints should be addressed to Mark H. Ebell, M.D. Route 2, Box 91A, Colbert, Georgia 30628.

Manuscript submitted September 24, 1990, and accepted in revised form May 18, 1991.
"Do-not-resuscitate" (DNR) orders have become widely used in American hospitals in the past decade, with up to $70 \%$ of patients having a DNR order written by the time of death $[1,2]$. Within the past century, an evolution of informed consent has taken place in American society that has allowed for an individual's autonomy-based right to consent to or refuse therapies [3]. As a result, competent patients have a right to refuse life-sustaining therapies and measures such as cardiopulmonary resuscitation in response to cardiopulmonary arrest [4]. These decisions are best made prospectively, rather than forcing the patient, physician, or patient's family to make such decisions in a time of medical crisis [5]. Advance directives such as the Living Will and Durable Power of Attorney are two instruments by which such prospective decisions can be legally formalized. Their limitations and applicability vary according to state law.

A DNR order specifically instructs the patient's health care provider to forego cardiopulmonary resuscitation should the patient undergo cardiac or respiratory arrest. Although some patients and physicians may view a DNR order as a decision to withdraw all medical care, such an order does not, by itself, preclude other medical interventions. DNR orders may be part of a broader order to provide "comfort care only," but this must be clarified with the patient or the surrogate decision-maker. Good communication between physicians, patients, and families is vital to accurately convey the implications of a DNR order, especially when one considers the difference in education and experience between the two groups.

Although patients report an interest in discussing DNR issues with their physicians, few report actually having these discussions. In a study by Frankl et al [6], 47\% of hospitalized patients wanted to discuss resuscitation with their physician, but only $16 \%$ actually did so. Similar figures were found in a recent study by the authors [7]. Of 338 outpatients surveyed, $67 \%$ reported having thought about the issue of their DNR status, $44 \%$ had discussed it with someone other than a physician, but only $11 \%$ had ever discussed resuscitation with a physician. Such data suggest significant barriers to communication between patients and their physicians.

Unfortunately, even when discussions about DNR orders do occur between physicians and pa- 


\section{TABLE}

Demographics of Family Physician Respondents

\begin{tabular}{|cc|}
\hline & Number (\%) \\
\hline Practice type & $41(31.3)$ \\
Group practice & $35(26.7)$ \\
Solo practice & $33(25.2)$ \\
Academic & $13(9.9)$ \\
Resident & $2(1.5)$ \\
Government & $7(5.3)$ \\
Other & \\
Postgraduate training & \\
Rotating (GP) & $21(16.0)$ \\
internship & \\
Family practice & $99(75.6)$ \\
residency & $4(3.0)$ \\
Other residency & $5(3.8)$ \\
None & $2(1.5)$ \\
Other & \\
Community size & $48(36.6)$ \\
$<10,000$ & $30(22.9)$ \\
$10-50,000$ & $53(40.4)$ \\
$>50,000$ & \\
Years in practice & $72(54.9)$ \\
$<11$ & $28(21.4)$ \\
$11-20$ & $31(23.7)$ \\
$>20$ &
\end{tabular}

tients or their proxies, they usually occur late in the patient's illness, often after extensive and painful medical interventions have occurred. In many cases, patients may no longer be competent and may be unable to participate in these discussions themselves. In one study, $86 \%$ of families but only $22 \%$ of patients had participated in discussions about DNR orders [8]. In another study, only $19 \%$ of patients who underwent resuscitation had discussed DNR orders with a physician prior to the event [9].

A number of studies have examined the role of the physician in DNR decision-making. In a survey of clinicians at a large medical center, $74 \%$ thought that the DNR order was primarily determined by the physician, while only $1 \%$ believed the patient was the primary decision-maker. Forty percent thought that the patient should have the right to be the primary decision-maker [10]. Non-biomedical factors such as mental retardation, dementia, and being a street person have been found to have a negative effect on the physician's decision to resuscitate [11]. Another study [12] found that the diagnosis of cancer had a negative impact on a physician's decision to resuscitate a patient.

Thus, physicians make DNR decisions with little direct patient input, based on factors that reflect quality of life and do not necessarily predict either prognosis or the outcome of resuscitation. In order to protect the patient's autonomy-based right to make health-care decisions, it is important that physicians explore and understand patients' values regarding terminal care. The purpose of this study is to compare attitudes and decision-making of family physicians concerning the DNR order with those of their patients.

\section{SUBJECTS AND METHODS}

A self-administered questionnaire was mailed to 202 family physicians selected at random from a list of Michigan Academy of Family Practice (MAFP) members. Additionally, the 32 faculty members and residents of the University of Michigan Department of Family Practice (UM staff) were asked to participate in the study. If a selected physician belonged to both groups, he or she was assigned to the MAFP group. Non-respondents received a second questionnaire and return envelope 3 weeks after the first mailing.

The questionnaire was divided into five sections. Part 1 gathered demographic information about the respondents. Part 2 explored past experience with DNR orders in the inpatient and outpatient settings. The third part asked the physician to rank who (other than the patient) they would want to have involved in the DNR decision-making process. Part 4 investigated the relative importance to physicians themselves of factors such as safety, pain, and being a burden on one's family. This set of values was adapted from a guide for creating the Values History of the patient by Doukas and McCullough [5]. Part 5 presented a number of scenarios, matched for age and medical prognosis but differing in a variety of biomedical and non-biomedical factors (i.e., drug use or no drug use, presence or absence of dementia). The pairs of scenarios were separated and listed in random order. In order to facilitate the comparison between physicians and patients, the wording for parts 3 to 5 of the physician questionnaire was identical to that of the patient questionnaire from the authors' prior study of family practice outpatients [7]. The group of outpatients used for comparison was from the University of Michigan Family Practice Center in Chelsea, Michigan (population 3,800), which serves the surrounding rural area as well as patients from the nearby city of Ann Arbor, Michigan (population 107,000 ). Of the 726 patients in the final study population, $372(51 \%)$ returned questionnaires, of which 34 (4.7\%) were incomplete, leaving 338 (47\%) for analysis.

Data were entered in a database using DBase III Plus [13] and were subsequently analyzed using the 


\section{TABLE II}

Percentage of Their Patients with Whom Family Physicians Discuss DNR Orders During an Admission to the Hospital

\begin{tabular}{|c|c|c|c|c|c|}
\hline \multirow{2}{*}{$\begin{array}{l}\text { Percentage } \\
\text { of Their } \\
\text { Inpatients }\end{array}$} & \multirow[b]{2}{*}{$\begin{array}{l}\text { All Family } \\
\text { Physicians }\end{array}$} & \multicolumn{2}{|c|}{ Type of Practice* } & \multicolumn{2}{|c|}{ Years in Practice ${ }^{\dagger}$} \\
\hline & & Academic & Private & $\begin{array}{r}\leq 10 \\
\text { Years }\end{array}$ & $\begin{array}{l}>10 \\
\text { Years }\end{array}$ \\
\hline $\begin{array}{c}<20 \\
21-40 \\
41-60 \\
61-80 \\
81-100 \\
\text { NR }\end{array}$ & $\begin{array}{c}58(46.0)^{\ddagger} \\
35(27.8) \\
23(18.2) \\
4(3.2) \\
6(4.8) \\
5(4.0)\end{array}$ & $\begin{array}{c}13(28.3) \\
18(39.1) \\
11(23.9) \\
2(4.3) \\
2(4.3) \\
0(0.0)\end{array}$ & $\begin{array}{c}42(55.3) \\
17(22.4) \\
9(11.8) \\
2(2.6) \\
4(5.2) \\
2(2.6)\end{array}$ & $\begin{array}{c}27(37.5) \\
25(34.7) \\
17(23.6) \\
2(2.8) \\
1(1.4) \\
0(0.0)\end{array}$ & $\begin{array}{c}31(57.4) \\
10(18.5) \\
6(11.1) \\
2(3.7) \\
5(9.3) \\
5(9.3)\end{array}$ \\
\hline
\end{tabular}

Academic physicians $=$ residents and faculty; private physicians $=$ physicians in solo or group practice; $N R=$ no response.

*Difference between academic and private physicians significant, $p=0.007$

tDifference between physiaicns in practice $\leq 10$ years and $>10$ years significant, $p=0.015$

† Values are numbers, with percents in parentheses.

SyStat [14] statistics program. Pairwise comparison of populations was done by independent Student $t$ tests utilizing separate variances. Differences in categorical variables were analyzed by the Pearson chi-square test.

\section{RESULTS}

Of 202 questionnaires mailed to MAFP members, 19 were returned with no forwarding address, two physicians had retired, and one was deceased. Of the remaining sample of 180 MAFP members, 103 returned completed questionnaires (57.2\%). Of 32 questionnaires given to UM staff members, 28 returned completed questionnaires $(87.5 \%)$; the response rate for both groups combined was $61.8 \%$. The relatively low return rates for MAFP members and outpatients, while not uncommon for a survey of community-based physicians and outpatients, may be considered a limitation of the study. Information about postgraduate training, type of practice, community size, and years in practice is found in Table I. Distribution of physicians by size of community was fairly evenly split between communities of less than $10,000,10,000$ to 50,000 , and greater than 50,000 inhabitants.

Hospitalized patients were seen by $90.1 \%$ of physicians, with an average of 11.8 inpatients per month. Of family physicians surveyed, $80 \%$ also cared for patients in the intensive care unit (ICU) or coronary care unit (CCU), and $87.8 \%$ had themselves attempted resuscitation of a patient under their care.

Ninety-seven percent of family physicians had discussed DNR orders with one of their patients, and the same number had actually written a DNR order. All of the physicians surveyed had discussed DNR orders at some time with a member of a patient's family. Information about the percentage of their hospitalized patients with whom physicians discussed DNR orders is summarized in Table II.
Physicians in private practice (rather than academic practice) and those who had been in practice for more than 10 years were less likely to routinely discuss DNR orders with their hospitalized patients. Physicians were asked if they had ever discussed DNR orders with patients or their families in a series of different locations. The greatest number of physicians $(93.7 \%)$ reported having had discussions with patients in hospital rooms, followed by the office $(90.6 \%)$, ICU/CCU (82.7\%), and emergency room (64.6\%). Discussions with families also occurred most often in hospital rooms $(96.2 \%)$, followed by the ICU/CCU (83.2\%), office (82.4\%), and emergency room $(73.3 \%)$.

In ranking the importance of persons other than the patient in making decisions about DNR status, physicians identified spouses, themselves, and children as most important. These responses were compared with those of family practice outpatients from our previous study (Table III). There were no significant differences in relative importance ( $p$ $<0.01$ ) when comparing responses for type of practice (academic versus private), family practice residency training (yes or no), community size (population less than 10,000 or greater than or equal to

\section{TABLE III}

Evaluation of the Relative Importance of Persons Other Than the Patient in Helping to Make DNR Decisions*

\begin{tabular}{lcc|}
\hline & $\begin{array}{c}\text { Family } \\
\text { Physicians }\end{array}$ & Patients \\
\hline Spouse & 4.8 & 4.8 \\
Physician & 4.7 & 4.6 \\
Children & 4.5 & 4.5 \\
Clergy & 3.3 & 3.2 \\
Nurse & 3.2 & 3.5 \\
Social worker & 2.7 & $2.1^{\dagger}$ \\
Friend & 2.6 & 2.8 \\
\hline
\end{tabular}

*A Likert scale was used, with $I=$ not important, $3=$ somewhat important, and $5=$ very important.

tSignificant, $p<0.001$. 


\section{TABLE IV}

Evaluation of Values Important to Family Physicians and Patients in Helping Make DNR Decisions*

\begin{tabular}{|c|c|c|}
\hline Value & $\begin{array}{l}\text { Physicians' } \\
\text { Score (order) }\end{array}$ & $\begin{array}{c}\text { Patients' } \\
\text { Score (order) }\end{array}$ \\
\hline $\begin{array}{l}\text { I want to be treated with dignity when I can no longer speak for myself } \\
\text { I want to maintain my capacity to think clearly } \\
\text { I want to be with my loved ones before I die } \\
\text { I want to be able to make my own decisions } \\
\text { I want to experience a comfortable dying process } \\
\text { I do not want to be a burden on my family } \\
\text { I want to be treated in accordance with my religious beliefs and traditions } \\
\text { I want to leave good memories of my last days to my loved ones } \\
\text { I want to avoid pain and suffering } \\
\text { I want to feel safe and secure }\end{array}$ & $\begin{array}{l}6.5(1) \\
6.2(2) \\
6.1(3) \\
5.9(4) \\
5.8(5) \\
5.7(6) \\
5.6(7) \\
5.5(8) \\
5.4(9) \\
5.0(10)\end{array}$ & $\begin{array}{l}6.6(2) \\
6.6(1) \\
6.4(6) \\
6.2(8) \\
6.4(5) \\
6.4(4) \\
5.7(10) \\
6.6(3) \\
5.9(9) \\
6.2(7)\end{array}$ \\
\hline
\end{tabular}

*A Likert scale was used, with $1=$ not important, $4=$ somewhat important, and $7=$ very important.

10,000 ), or number of inpatients admitted per month (less than five or greater than or equal to five).

When asked about their own views on quality of life and resuscitation, $94.7 \%$ of physicians preferred preserving a good quality of life, even if it meant not living as long. Only $2.3 \%$ wanted to live as long as possible, regardless of quality of life ( $3 \%$ did not respond to this question).

Family physicians were also asked to rank a series of values according to how important they are to the physician himself or herself. These responses were compared with those of the family practice outpatients from our previous study (Table IV). Both patients and physicians ranked "being able to think clearly" and "being treated with dignity" most highly. Patients placed more value than physicians on "leaving good memories of their last days to their loved ones," while physicians ranked "being with their loved ones" and "being able to make their own decisions" higher than their patients. There was no significant difference $(p<0.01)$ in responses by type of practice, residency training, community size, or number of inpatients per month.

Responses to scenarios paired by a variety of biomedical and non-biomedical factors are listed in Table V. Physicians were less likely to recommend resuscitation for older patients, intravenous drug users, patients with Alzheimer's disease, patients with severe pain, alcoholic patients, disabled patients, and patients with cancer as a diagnosis. There was no significant difference $(p<0.01)$ in

\section{TABLE V}

Impact of a Variety of Biomedical and Non-Biomedical Factors on Physicians' DNR Decisions (exact wording of scenarios is shown)*

\begin{tabular}{|c|c|c|}
\hline Scenario & $\begin{array}{l}\text { Difiering } \\
\text { Factor }\end{array}$ & $\begin{array}{l}\text { Physicians' } \\
\text { Rating }\end{array}$ \\
\hline $\begin{array}{l}\text { A 90-year-old man with a heart attack. } \\
\text { A } 70 \text {-year-old man with a heart attack. } \\
\text { A } 50 \text {-year-old man with a heart attack. }\end{array}$ & $\mathrm{Age}^{\dagger}$ & $\begin{array}{l}3.2 \\
2.1 \\
1.3\end{array}$ \\
\hline $\begin{array}{l}\text { A 24-year-old man with an infected heart valve due to heroin abuse. } \\
\text { A 30-year-old woman with heart disease due to rheumatic fever. }\end{array}$ & Drug use ${ }^{\dagger}$ & $\begin{array}{l}1.6 \\
1.3\end{array}$ \\
\hline $\begin{array}{l}\text { A 72-year-old woman with severe Alzheimer's disease and pneumonia. } \\
\text { A 73-year-old man who is otherwise well, but has a pneumonia. }\end{array}$ & Alzheimer's disease $^{\dagger}$ & $\begin{array}{l}4.4 \\
1.6\end{array}$ \\
\hline $\begin{array}{l}\text { A 64-year-old womanwith severe pain due to bone cancer. } \\
\text { A } 64 \text {-year-old woman with terminal breast cancer, but minimal pain. }\end{array}$ & $\operatorname{Pain}^{\dagger}$ & $\begin{array}{l}4.5 \\
3.5\end{array}$ \\
\hline $\begin{array}{l}\text { A 57-year-old man with end-stage liver disease due to alcohol abuse. } \\
\text { A 52-year-old man who had hepatitis, and now suffers from liver failure. }\end{array}$ & Alcohol use ${ }^{\dagger}$ & 3.8 \\
\hline $\begin{array}{l}\text { A 78-year-old woman who is confined to a wheelchair and has a pneumonia. } \\
\text { A 73-year-old man who is otherwise well, but has a pneumonia. }\end{array}$ & Wheelchair ${ }^{\dagger}$ & $\begin{array}{l}2.5 \\
1.6\end{array}$ \\
\hline $\begin{array}{l}\text { A 64-year-old woman with terminal breast cancer, but minimal pain. } \\
\text { A 68-year-old woman with severe, end-stage congestive heart failure. }\end{array}$ & Cancer as diagnosis $^{\dagger}$ & $\begin{array}{l}3.5 \\
3.9\end{array}$ \\
\hline $\begin{array}{l}\text { An } 80 \text {-year-old man in a nursing home. } \\
\text { An } 82 \text {-year-old man cared for by his wife in their home. }\end{array}$ & Nursing home & $\begin{array}{l}2.8 \\
2.7\end{array}$ \\
\hline
\end{tabular}

*Scenarios were matched for medical prognosis, but differ by a variety of biomedical and non-biomedical factors. A Likert scale was used, with $1=$ definitely should resuscitate and $5=$ definitely should nol resuscitate.

Difference between matched pairs/trios of scenarios significant, $p<0.001$. 
responses by type of practice or residency training. Physician responses were compared with patient responses to the same scenarios (Table VI). Although there were differences between patients and physicians regarding the exact value on the Likert scale given to each scenario, these were largely differences of degree and not overall order in the decision to resuscitate. When compared with patient evaluations of the same scenarios, physicians did place significantly less importance than patients on the presence of drug or alcohol use when recommending resuscitation.

\section{COMMENTS}

This study confirms that the DNR order has indeed become a widely used part of medical practice in both academic and private settings. Of physicians surveyed, $97 \%$ had written such an order for one of their patients. In addition, the vast majority (90.6\%) had discussed DNR orders in their offices, outside the acute-care setting. This is a somewhat higher figure than the $73 \%$ reported by Tunzi et al [15] in a similar survey of family physicians in California. Most physicians, however, still reserve these discussions for a minority of their patients; only $8 \%$ discussed DNR orders with over $60 \%$ of their hospitalized patients.

In this study, academic family physicians (faculty and residents) reported discussing resuscitation with a greater percentage of their hospitalized patients than their private practice counterparts. This may be due to a greater emphasis on the bioethical and psychosocial aspects of medicine in current family practice training programs. Physicians who had been in practice 10 years or less were also more likely to discuss DNR orders with their hospitalized patients than those who had been in practice for a longer period. One can speculate that physicians who had their practice style shaped in the era before the recent emphasis on patient autonomy may be less comfortable with, or place less value on, DNR discussions.

In response to the question of who should be involved in the discussion to establish DNR status, patients and physicians agreed to a remarkable degree. The consensus between the two groups is that spouses, physicians, and children are the most important decision-makers. The only significant difference was a greater value placed on the input of social workers by physicians, perhaps because of their greater familiarity with this group of health care professionals. Previous work by the authors suggests that patients with a poor health score value the input of clergy and friends more highly than do patients with an average or above average health score [7]. These preferences might be considered when planning family meetings.

\begin{tabular}{|c|c|c|}
\hline \multicolumn{3}{|c|}{$\begin{array}{l}\text { Comparison of Family Physician and Patient Evaluations of Medical } \\
\text { Scenarios, Matched for Age and Medical Prognosis but Differing by a } \\
\text { Variety of Biomedical and Non-Biomedical Factors* }\end{array}$} \\
\hline $\begin{array}{l}\text { Discriminant } \\
\text { Factor }\end{array}$ & $\begin{array}{l}\text { Physicians' } \\
\text { Rating }\end{array}$ & $\begin{array}{l}\text { Patients' } \\
\text { Rating }\end{array}$ \\
\hline $\begin{array}{l}90 \text {-year-old } \\
70 \text {-year-old } \\
50 \text {-year-old }\end{array}$ & $\begin{array}{l}3.2 \\
2.1 \\
1.3\end{array}$ & $\begin{array}{l}3.6 \\
2.2 \\
1.4\end{array}$ \\
\hline $\begin{array}{l}\text { Intravenous drug use }{ }^{\dagger} \\
\text { No intravenous drug use }{ }^{\dagger}\end{array}$ & $\begin{array}{l}1.6 \\
1.3\end{array}$ & $\begin{array}{l}2.4 \\
1.8\end{array}$ \\
\hline $\begin{array}{l}\text { Alzheimer's } \\
\text { No Alzheimer's }\end{array}$ & $\begin{array}{l}4.4 \\
1.6\end{array}$ & $\begin{array}{l}4.1 \\
1.5\end{array}$ \\
\hline $\begin{array}{l}\text { Pain }^{\dagger} \\
\text { No pain }\end{array}$ & $\begin{array}{l}4.5 \\
3.5\end{array}$ & $\begin{array}{l}3.9 \\
2.9\end{array}$ \\
\hline $\begin{array}{l}\text { Alcoholism } \\
\text { No alcoholism }{ }^{\dagger}\end{array}$ & $\begin{array}{l}3.8 \\
3.5\end{array}$ & $\begin{array}{l}3.7 \\
2.9\end{array}$ \\
\hline $\begin{array}{l}\text { Wheelchair use } \\
\text { No wheelchair use }\end{array}$ & $\begin{array}{l}2.5 \\
1.6\end{array}$ & $\begin{array}{l}2.7 \\
1.5\end{array}$ \\
\hline $\begin{array}{l}\text { Cancer diagnosis }{ }^{\dagger} \\
\text { Non-cancer diagnosis }\end{array}$ & $\begin{array}{l}3.5 \\
3.9\end{array}$ & $\begin{array}{l}2.9 \\
3.7\end{array}$ \\
\hline $\begin{array}{l}\text { Nursing home resident }{ }^{\dagger} \\
\text { Cared for at home }\end{array}$ & $\begin{array}{l}2.8 \\
2.7\end{array}$ & $\begin{array}{l}3.2 \\
3.1\end{array}$ \\
\hline
\end{tabular}

${ }^{*}$ L Likert scale was used, with $1=$ definitely should resuscitate and $5=$ definitely should not resuscitate.

the difference between the patient and physician ratings of this scenario is significant at $p \leq 0.001$.

Values clarification questionnaires can be a helpful aid for both patients and families struggling with DNR issues. Comparison in this study of the rank order given to a set of values by patients and family physicians reveals both similarities and differences in important values to be considered in deciding DNR status. Physicians should think carefully about how their values may differ from those of their patients. Physicians can have a significant impact on the alleviation of patient suffering, whether or not patients are able to die at home, and the degree to which patients can maintain autonomous decision-making capacity, dignity, and the ability to think clearly. For example, if a patient especially valued the ability to think clearly, and placed less value on avoiding pain and suffering, it would be most appropriate to minimize the use of pain medications that cloud consciousness.

Like patients, physicians weigh both biomedical and non-biomedical factors when making DNR decisions. Age, drug or alcohol use, Alzheimer's disease, pain, and wheelchair use were all associated with a decreased likelihood that both physicians and patients would recommend resuscitation. Clearly, quality-of-life issues are important to both groups in making DNR decisions.

The diagnosis of cancer, when compared with severe congestive heart failure (two diseases with roughly equivalent prognoses), was associated with 
a stronger recommendation to resuscitate from both groups. This differs from previously reported data of Lawrence and Clark [12], who found that a diagnosis of cancer negatively affected the decision by physicians to resuscitate. The patient in our scenario was specifically not experiencing any pain, something which is often associated with cancer patients, and which also affects the decision to resuscitate. It may be that prior studies have failed to separate concerns about pain from the presence of cancer as a diagnosis. This would further support the importance of quality-of-life issues such as the presence or absence of pain in DNR decision-making. Interestingly, patients were less likely than physicians to recommend resuscitation for patients with a history of drug or alcohol use. This may be due to a greater tendency for physicians to treat substance abuse as a potentially treatable illness, rather than as a moral issue.

Patients and physicians approach the process of deciding DNR status from very different vantage points, with different experiences and levels of medical expertise. Patients may lack specific prognostic information available to physicians, while physicians often do not know the patient's values and support systems. There are important similarities between the two groups, especially regarding the choice of who should be involved in the decision-making process and the importance of qualityof-life issues. However, there are also significant differences, especially regarding the values and experience of the two groups.

Because the physician usually controls the medical interview, we encourage all physicians to approach their patients to discuss DNR issues, especially those who are over 70 or who have a chronic illness and are therefore less likely to benefit from resuscitation $[16,17]$. A timely, caring, and open ex- change of information involving the appropriate individuals and taking into account the patient's prognosis, quality of life, and value system is vital to humane DNR decision-making. This approach will allow patients and their physicians to better manage the medical technology that faces all of us as we near life's end.

\section{REFERENCES}

1. Ruark JE, Raffin TA, and the Stanford University Medical Center Committee on Ethics. Initiating and withdrawing life support: principles and practice in adult medicine. N Engl I Med 1988; 318: 25-30.

2. Jonsson PV, MCNamee M, Campion EW. The "do not resuscitate" order. A profile of its changing use. Arch Intern Med 1988; 148: 2373-5.

3. Faden R, Beauchamp T. A history and theory of informed consent. New York: Oxford University Press, 1986: 119-43.

4. President's Commission for the Study of Ethical Problems in Medicine and Biomedical and Behavioral Research. Deciding to forego life-sustaining treatment: ethical, medical and legal issues in treatment decisions. Washington, DC: U.S. Government Printing Office, 1983: 89.

5. Doukas DJ, McCullough LB. Handbook of geriatric assessment. Rockville: Aspen Publishers, 1988: 111-24.

6. Franki D, Oye RK, Bellamy PE. Attitudes of hospitalized patients toward life support: a survey of 200 medical inpatients. Am J Med 1989; 86: 645-50.

7. Ebell MH, Smith MA, Seifert KG, Polsinelli $K$. The do-not-resuscitate order: outpatient preferences and decision-making. J Fam Pract 1990; 31: 630-6.

8. Bedell SE, Pelle D, Maher PL, Cleary PD. Do-not-resuscitate orders for criticalIy ill patients in the hospital. JAMA 1986; 256: 233-7.

9. Bedell SE, Delblanco TL. Choices about cardiopulmonary resuscitation in the hospital. When do physicians talk with patients? N Engl J Med 1984; 310: 1089-93.

10. Perry SW, Schwartz HI, Amchin J. Determining resuscitation status: a survey of medical professionals. Gen Hosp Psychiatry 1986; 8: 198-202.

11. Farber NJ, Bowman SM, Major DA, Green WP. Cardiopulmonary resuscitation: patient factors and decision making. Arch Intern Med 1984; 144: 2229-32. 12. Lawrence VA, Clark GM. Cancer and resuscitation: does the diagnosis affect the decision? Arch Intern Med 1987; 147: 1637-40.

13. DBase III Plus. Provo, Utah: Ashton-Tate Inc., 1986.

14. SyStat: the system for statistics. Evanston, Illinois: Systat Inc., 1989.

15. Tunzi M, Wollitzer AO, Blossom HJ. Discussion of code status with outpatients. J Fam Pract 1988; 26: 572-3.

16. Taffet GE, Teasdale TA, Luchi RJ. In-hospital cardiopulmonary resuscitation. JAMA 1988; 260: 2069-72.

17. Murphy DJ. Murray AM. Robinson BE. Campion EW. Outcomes of cardiopulmonary resuscitation in the elderly. Ann Intern Med 1989; 111: 199-205. 